\title{
Perinatal outcome associated with oligohydramnios at term
}

\author{
Nikita Gandotra, Neha Mahajan*, Akriti Manhas
}

Department of Obstetrics and Gynecology, SMGS Hospital, Jammu, Jammu and Kashmir, India

Received: 26 July 2020

Revised: 08 August 2020

Accepted: 13 August 2020

\section{*Correspondence:}

Dr. Neha Mahajan,

E-mail: nikigandotra@gmail.com

Copyright: () the author(s), publisher and licensee Medip Academy. This is an open-access article distributed under the terms of the Creative Commons Attribution Non-Commercial License, which permits unrestricted non-commercial use, distribution, and reproduction in any medium, provided the original work is properly cited.

\section{ABSTRACT}

Background: Oligohydramnios is a severe and common complication of pregnancy and its incidence is reported to be around 1 to $5 \%$ of total pregnancies. The aim of this study was to perinatal outcome of oligohydramnios (AFI <5) at term.

Methods: A prospective study was conducted in which 200 patients at term with oligohydramnios AFI $<5 \mathrm{~cm}$ with intact membranes were analyzed for perinatal outcome.

Results: There were increased chances of FHR decelerations, thick meconium, increased LSCS, low Apgar score at 5 minutes, birth weight $<2.5 \mathrm{~kg}$, admission to NICU in pregnancy with oligohydramnios.

Conclusions: An amniotic fluid index (AFI) of $<5 \mathrm{~cm}$ detected after 37 completed weeks of gestation is an indicator of poor perinatal outcome. Determination of AFI can be used as an adjunct to other fetal surveillance methods that helps to identify those infants at risk of poor perinatal outcome.

Keywords: Amniotic fluid index $<5 \mathrm{~cm}$, Oligohydramnios, Perinatal outcome

\section{INTRODUCTION}

Amniotic fluid is a clear, slightly yellowish liquid that surrounds the fetus during pregnancy. It is contained in the amniotic sac. The fluid is faintly alkaline with low specific gravity of 1.010. Amniotic fluid volume is related to gestational age. It measures about $50 \mathrm{ml}$ at 12 weeks, $400 \mathrm{ml}$ at 20 weeks and reaches peak of 1 litre at 36-38 weeks. Thereafter the amount diminishes till at term it measures about $600-800 \mathrm{ml}^{1}{ }^{1}$ In the first half of pregnancy, the composition of fluid is almost identical to a transudate of plasma. But in late pregnancy, the composition is very much altered. The composition includes water $98-99 \%$ and solids (1-2\%). Solid constituents are organic, inorganic and suspended particles. $^{2}$ It is a common obstetric complication, occurring in 0.5 to $>5 \%$ pregnancies depending on the definition of oligohydramnios used and the population studied. ${ }^{3}$ The incidence increases to approximately $11 \%$ in postdated pregnancies. ${ }^{1}$
Oligohydramnios is associated with a high rate of pregnancy complications and increased perinatal morbidity and mortality. During antenatal fetal surveillance, amniotic fluid assessment is a crucial barometer to know the fetal status. ${ }^{4}$ Primal sonographic sign of an obstetrical issue is abnormal amniotic fluid volume..$^{5}$

Compression of uterine wall and adherent fetal parts and prolonged external compression and abnormal fetal development due to prolonged oligohydramnios boost the risk of pulmonary hypoplasia includes fetal skeletal and facial deformities. Oligohydramnios also increase the caesarean section rate for fetal distress up to $41 \%$. It also escalates the maternal morbidity and mortality by maternal complications like inertia, increased operative interference due to malpresentation ultimately. ${ }^{6}$

Thus, amniotic fluid index (AFI) assessed antepartum or intrapartum would help to identify women who need 
increased antepartum surveillance for pregnancy complications. Keeping in mind the above knowledge, the present study was carried out to find whether oligohydramnios can be used as a predictor of adverse perinatal outcome in non-complicated pregnancies at term.

Amount of liquor amnii in the present study was assessed by ultrasonography. Though there are various methods for sonographic assessment of amniotic fluid, AFI was taken as the criteria.

The present study has been done with an objective to determine the maternal and perinatal outcome of term pregnancy with oligohydramnios in authors tertiary care hospital.

\section{METHODS}

A prospective hospital-based study was carried out in the department of obstetrics and gynecology, SMGS hospital from June 2019 to January 2020. In this study, 200 patients with gestational age $\geq 37$ weeks with oligohydramnios (AFI $<5 \mathrm{cms}$ ) with intact membranes were analysed for perinatal outcome.

\section{Inclusion criteria}

Inclusion criteria of this study were women with singleton, non-anomalous fetus with intact membranes and gestational age 37-40 weeks.

\section{Exclusion criteria}

Women with premature rupture of membranes, known fetal and chromosomal anomaly, severe pre-eclampsia, pos-term pregnancy were excluded from the study.

On admission a detailed history was taken, clinical examination was performed and gestational age assessed. AFI was determined by the Phelans technique using transabdominal sonography. AFI was measured by dividing the uterus into four quadrants. When the maximum vertical pocket of liquor is less than $2 \mathrm{~cm}$ or when AFI is less than $5 \mathrm{~cm}$. AFI $5-8 \mathrm{~cm}$ as borderline oligohydramnios and AFI $8-18 \mathrm{~cm}$ as normal amniotic fluid index. ${ }^{1}$

NST was performed for all patients. Parameters noted were MSAF, the mode of delivery, birth weight, Apgar score at 1 and 5 minutes. Results were analysed with special emphasis on perinatal outcome by using percentage and proportion.

\section{RESULTS}

It was observed that $128(64 \%)$ women with oligohydramnios were in age group of 20-25 years (Table $1)$.
Table 1: Age and oligohydramnios.

\begin{tabular}{|lcc|}
\hline Age group in years & Number & Percentage \\
\hline $\mathbf{2 0 - 2 5}$ & 128 & 64 \\
\hline $\mathbf{2 6 - 3 0}$ & 44 & 22 \\
\hline $\mathbf{> 3 0}$ & 28 & 14 \\
\hline Total & 200 & 100 \\
\hline
\end{tabular}

A total $34 \%$ of the females with oligohydramnios were primigravida and $66 \%$ were multigravida in this study (Table 2).

Table 2: Parity and oligohydramnios.

\begin{tabular}{|lll|}
\hline Parity & Number & Percentage \\
\hline Primigravida & 68 & 34 \\
\hline Multigravida & 132 & 66 \\
\hline
\end{tabular}

A total $32 \%$ patients in this study had AFI of 4 on admission followed by $25 \%$ females with AFI of $5.2 \%$ females presented with absent liquor on admission (Table 3).

Table 3: AFI on admission.

\begin{tabular}{|lll|}
\hline AFI & Number & Percentage \\
\hline $\mathbf{0}$ & 4 & 2 \\
\hline $\mathbf{1}$ & 16 & 8 \\
\hline $\mathbf{2}$ & 36 & 18 \\
\hline $\mathbf{3}$ & 30 & 15 \\
\hline $\mathbf{4}$ & 64 & 32 \\
\hline $\mathbf{5}$ & 50 & 25 \\
\hline Total & 200 & 100 \\
\hline
\end{tabular}

Table 4: CTG on admission.

\begin{tabular}{|lll|}
\hline & Number & Percentage \\
\hline Normal & 122 & 61 \\
\hline Abnormal & 78 & 39 \\
\hline
\end{tabular}

A total $61 \%$ patients had CTG reactive at the time of admission and $39 \%$ patients had abnormal CTG. The rate of abnormal CTG was statistically significant (Table 4).

Table 5: Color of liquor at rupture of membranes.

\begin{tabular}{|lll|}
\hline Colour & Number & Percentage \\
\hline Normal & 142 & 71 \\
\hline Meconium stained & 58 & 29 \\
\hline
\end{tabular}

A total $29 \%$ of patients with oligohydramnios had meconium stained liquor in this study (Table 5).

Caesarean for fetal distress was higher in women with oligohydramnios. Caesarean section was performed in $38 \%$ of patients in this study maximum for fetal distress (Table 6). 
Table 6: Mode of delivery.

\begin{tabular}{|lll|}
\hline Mode of delivery & Number & Percentage \\
\hline Vaginal & 142 & 71 \\
\hline LSCS & 58 & 29 \\
\hline
\end{tabular}

Birth weight $<2.5 \mathrm{~kg}$ was found in $66 \%$ patients and $>2.5$ $\mathrm{kg}$ in $34 \%$ of patients. $6 \%$ babies required NICU admission with birth weight $<2.5 \mathrm{~kg}$ (Table 7).

Table 7: Perinatal outcome.

\begin{tabular}{|lll|}
\hline $\begin{array}{l}\text { Outcome } \\
\text { Birth weight }\end{array}$ & Number & NICU admissions \\
\hline$<2.5 \mathrm{~kg}$ & $132(66)$ & $12(6)$ \\
\hline$>2.5 \mathrm{~kg}$ & $68(34)$ & - \\
\hline Apgar score & & \\
\hline$<7$ at $1 \mathrm{~min}$ & $66(33)$ & $26(13)$ \\
\hline$<7$ at 5 min & $8(4)$ & $6(3)$ \\
\hline MAS & $24(12)$ & $4(2)$ \\
\hline $\begin{array}{l}\text { Early neonatal } \\
\text { death }\end{array}$ & $4(2)$ & - \\
\hline Still birth & $2(1)$ & - \\
\hline
\end{tabular}

MAS: meconium aspiration syndrome.

Apgar score at 1 minute was $<7$ in $33 \%$ with $13 \%$ NICU admissions and Apgar $<7$ at 5 minutes was found in $4 \%$ with $3 \%$ NICU admissions. $12 \%$ babies had meconium aspiration syndrome (MAS) and 2\% had NICU admission. Early neonatal death was observed in $2 \%$ patients and $1 \%$ still birth was also observed.

\section{DISCUSSION}

Women who are at risk for potentially adverse perinatal outcome can be identified by the assessment of amniotic fluid volume in antenatal period. Ultrasound examination during that period is a sensitive and reliable method of assessing the amniotic fluid and to detect oligohydramnios or polyhydramnios. In a pregnancy complicated by oligohydramnios and fetal growth restriction closed fetal surveillance is important because of associated morbidity and delivery is recommended for fetal or maternal indication. ${ }^{7}$

In this study maximum number $(64 \%)$ of women were in age group of 20-25 years. These findings are comparable with the study done by Biradar et al, Chaudhari et al, but contrast result was found in study done by Vidyasagar et al $(80.49 \%){ }^{8-10}$ Almost $34 \%$ participants were primigravida in this study. Results were similar to the study done by Biradar et al, Chaudhari et al, Vidyasagar et al where primigravida participants were $33.0 \%, 35.8 \%$ and $46.3 \%$ respectively. ${ }^{8-10}$ In the study done by Casey et al there were no significant relations of age and parity with oligohydramnios. ${ }^{6}$

In this study, 58 patients had meconium staining of amniotic fluid which was $29 \%$. There was a significant relation between the meconium staining of amniotic fluid and oligohydramnios.

A total $62 \%$ patients in this study had vaginal delivery while $38 \%$ patients underwent caesarean section out of which $42.3 \%$ had caesarean section for fetal distress. Chauhan et al found that AFI $<5 \mathrm{~cm}$ was associated with an increased incidence of caesarean section for fetal distress. ${ }^{11}$

A total $66 \%$ babies born had birth weight less than $2.5 \mathrm{~kg}$ out of which 10 had NICU admissions. 33\% had Apgar score $<7$ at I minute, $12 \%$ had meconium aspiration syndrome. In study conducted by Chaudhari et al, $65.3 \%$ babies had weight $<2.5 \mathrm{~kg}$ while it was $38.6 \%$ in the study conducted by Biradar et al. ${ }^{8,9}$ In the study by Sowmya et al, low birth weight was seen in 48\%, Apgar score $<7$ seen in $14 \%$ and $14 \%$ were admitted in NICU. ${ }^{12}$

Another study by Madhavi et al found the incidence of meconium stained liquor in 36\%, 20\% had Apgar score less than 7 at 5 minutes, incidence of NICU admission in $34 \%$, incidence of meconium aspiration syndrome (MAS) in $6 \% .^{13}$

In the present study there were $2 \%$ early neonatal deaths and $1 \%$ stillbirth similar to the study conducted by Chuadhari et al $(1.2 \%){ }^{9}$

To identify women who need increased antepartum surveillance for pregnancy complications, antepartum measurement of AFI can very much helpful. ${ }^{11}$ Caesarean section is mostly required for the cases with an hydramnios and intrapartum fetal heart rate abnormalities. Babies are relatively more prone for certain complications like intrapartum fetal distress, MSAF and birth asphyxia. ${ }^{14}$

\section{CONCLUSION}

Oligohydramnios in obstetrics is a frequent occurrence and it points towards intensive surveillance and proper ante-natal and post-natal care. Due to high perinatal morbidity and mortality, the incidence of LSCS increases. Oligohydramnios is significantly associated with abnormal fetal growth and IUGR. So timely intervention by an obstetrician will be help in improving the perinatal outcome.

Funding: No funding sources

Conflict of interest: None declared

Ethical approval: The study was approved by the Institutional Ethics Committee

\section{REFERENCES}

1. Phelan JP, Smith CV, Small M. Amniotic fluid volume assessment with four quadrant technique at 36-42 weeks of gestation. J Repod Med. 1987;32:540-2. 
2. Dutta DC. Textbook of obstetrics, $8^{\text {th }}$ edition; 2015:43-44:250-251.

3. Zhang J, Troendle J, Meikle S, Klebanoff MA, Rayburn WF. Isolated oligohydramnios is not associated with adverse perinatal outcomes. $\mathrm{Br} \mathrm{J}$ Obstet Gynaecol. 2004;111(3):220-5.

4. Bansal D, Deodhar P. A clinical study of maternal and perinatal outcome in oligohydramnios. J Res Med Den Sci. 2015;3(4):312-6.

5. Williams Obstetrics. Cunningham FG, Gant NF, Leveno KJ, Gilstrap LC III, Hauth JC, Wenstrom KD: $21^{\text {st }}$ Edition USA; McGraw Hill. Fetal Growth and Development. Chapter 7; 2003: 142-143.

6. Casey BM, McIntire DD, Bloom SL, Lucas MJ, Santos R, Twickler DM, et al. Pregnancy outcomes after antepartum diagnosis of oligohydramnios at or beyond 34 weeks of gestation. Am J Obstet Gynecol. 2000;182(4):909-12.

7. Kofinas A, Kofinas G. differences in amniotic fluid patterns and fetal biometric parameters in third trimester pregnancy with and without diabetes. J Matern Foetal Neonatal Med. 2006;19(10):633-8.

8. Biradar KD, Shamanewadi AN. Maternal and perinatal outcome in oligohydramnios: study from a tertiary care hospital, Bangalore, Karnataka, India. Int J Reprod Contracept Obstet Gynecol. 2016;5:2291-4.

9. Chaudhari KR, Chaudhari KR, Desai OM. Perinatal outcome associated with oligohydramnios in third trimester. Int J Reprod Contracept Obstet Gynecol. 2017;6:72-5.
10. Vidyasagar V, Chutani N. Fetomaternal outcome in cases of oligohydramnios after 28 weeks of pregnancy. Int J Reprod Contracept Obstet Gynecol. 2015;4:152-6.

11. Chauhan SP, Sanderson M. Perinatal outcome and amniotic fluid index in the antepartum and intrapartum periods: a meta-analysis. Am J Obstet Gynecol. 1999;181(6):1473-8.

12. Sowmya K, Varghese B, Borkar YB. Effect of isolated oligohydramnios in otherwise normal term pregnancy. Int J Biomed Res. 2014;5(2):98-101.

13. Madhavi K, Rao PC. Clinical study of oligohydramnios, mode of delivery and perinatal outcome. IOSR J Dent Med Sci. 2015;14(4):6-11.

14. Driggers RW, Holcroft CJ. An amniotic fluid index less than or equal to $5 \mathrm{~cm}$ within 7 days of delivery in the third trimester is not associated with decreasing umbilical arterial ph and base excess. J Perinatol. 2004; 24(2):72-6.

15. Ghosh R, Oza H, Padhiyar B. Maternal and fetal outcome in oligohydramnios: study from a tertiary care hospital, Ahmedabad, India. Int $\mathbf{J}$ Reprod Contracept Obstet Gynecol. 2018;7:907-10.

Cite this article as: Gandotra N, Mahajan N, Manhas A. Perinatal outcome associated with oligohydramnios at term. Int J Reprod Contracept Obstet Gynecol 2020;9:3576-9. 